\title{
Socially-enhanced Variants of Mobile Bingo Game: Towards Personalized Cognitive and Social Engagement among Seniors
}

\author{
Chien-Sing Lee, Shanice Wei-Ling Chan, Sheng-Yee Guy \\ Department of Computing and Information Systems \\ Sunway University, Malaysia. \\ chiensing1@sunway.edu.my, 15049190@imail.sunway.edu.my, sheng.g2@imail.sunway.edu.my
}

\begin{abstract}
Elderlies often feel isolated or disregarded. This may lead to depression, lack of cognitive and social engagement. This project thus aims to engage the elderlies through three variants of a mobile bingo game application designed based on Norman's usability principles. This paper presents the design and development of three variants of the mobile bingo game to suit the needs of senior citizens. User testing outcomes on user experience, usability and cognitive load are positive.
\end{abstract}

Keywords - variants, bingo game, elderlies, cognitive, social engagement

\section{INTRODUCTION}

Malaysia is going to be an aging country by 2035 , when $15 \%$ of its population will consist of those aged 60 and above [1]. They slowly become frail and physically challenged. It is also generally accepted that some elderlies are neglected or isolated in terms of communication with the younger generations or social activities due to their lack of pace physically and mentally. Hence, some may be facing depression or loneliness but have nothing or no one to confide in.

A research was conducted on the elderlies located in Sepang, Selangor state in Malaysia alone and it concluded that $7.6 \%$ elderlies were facing depression [2]. Depression has become widespread and reported to have reached as high as $48.8 \%$ in the community and $67 \%$ in nursing homes [3]. Furthermore, as majority of the elderlies are not techsavvy, they are unable to relish in the wonders of mobile entertainment and a lack of social connection with people in general and with family [4].

When the elderly percentage increases, so does the need for old folks' homes. Apart from being separated from family and home, many experience similar boredom, depression, loneliness and more often, the loss of faith. Hence, many senior citizens (especially those in old folks' homes) require assistance be it mentally, emotionally or physically. However, most nursing centres are not managed properly as they are not able to pay attention to nor trained to tend to each individual, especially those with Dementia or Alzheimer's disease [5]. Technology and telecommunication can liberate the current situation.

\section{A. Problem Statement}

Playing games traditionally can help address the above problems. Digital games should not only bring benefit to them in the way of convenience and appeal, but also to make possible social connections. Statistics [6] show that elderlies who maintain social interactions have a much lower chance of declining in health. This may ease their depression/aggression by allowing them to enjoy.

Many technology creators produce mobile technology that are tech-savvy and posh, which may excel in terms of attracting the younger generations and working adults. However, the current issues faced nowadays is that the elderlies have problems in learning how to utilize mobile devices. It is reported that $77 \%$ of senior citizens require assistance from someone else in the process of setting up their device alone [7]. Furthermore, elderly brains learn, but maybe too much [8]. As most software these days are designed to support younger users, mobile interfaces may come off as intimidating and complicated and may result in demotivation.

\section{B. Objectives}

The goal for this project is to provide entertainment/engagement and to alleviate the elderlies' depression, loneliness and anxiety by creating variants of a bingo app. We scope the key problem to the interface design.

[9] highlights that learnability is sometimes more important than usability as some applications would require embedded features such as Google map. This however, requires good design of affordances. As such, we will apply suitable mobile usability principles and functions to cater to the needs of the target audience.

Although derived from gambling, Bingo is popular among children, teenagers and the elderlies [10]. Bingo relates to the elderlies in a way that they can obtain numerous benefits such as sharpening their cognitive abilities, encouraging them to be more socialable (which reduces depression and anxiety) while preserving physical health. Moreover, by being a part of a bingo community, it provides an opportunity for the elderlies to stay acquainted with family and friends. 


\section{Contribution}

Together with another related project, i.e., a Web and augmented-reality enhanced mobile application [11], images are shared interchangeably, creating modularity, extensibility and hopefully, personalization and greater sustainability. Both works are loosely coupled aimed at generating big data and to enable more meaningful analytics. The latter is presented in another paper, one of which is in the IEEM 2017 conference.

\section{RELATED WORK}

Mobile applications need to go through usability tests to ensure they are both efficient and error-free. According to Norman [12], a standard application should involve several aspects of mobile games' usability such as consistency, visibility, affordance, mapping, feedback and constraints. Nielsen's usability tests however, cover efficiency, satisfaction, learnability, memorability and errors.

To review the various types of Bingo games, we looked at those at the Play Store where users all over the globe provide their feedback [13]. The games were downloaded and installed for testing. Then, we compared using both usability principles. We choose to design mainly based on Norman's principles because they cater to our objectives of designing for the elderlies by increasing/improving affordances.

The proposed solution would consist of attractive interfaces with minimal yet clear instructions or texts to provide easy navigation. After researching on reviews and feedback provided by users of various age groups, it is important that the game does not charge users money for ingame products as the main objective of this development is to provide emotional and mental assistance to the elderly through virtual entertainment instead of earning profit. Furthermore, the game would be made offline so that there is no need or requirement to constantly connect to the Internet, thus reducing cost.

\section{METHODOLOGY}

\section{A. Chosen Methodology for Bingo App}

The methodology chosen for this project is the Agile Software Development Methodology (Fig. 1) [14]. The reason is because of quality control. Before the Bingo app is finalized, there is room for constant testing throughout the process of creation therefore reducing risks of errors, giving the developer an early heads-up. Similarly, it also promotes error prevention and is flexible enough to fulfil the clients' needs regardless of whether the development cycle has already started or not.

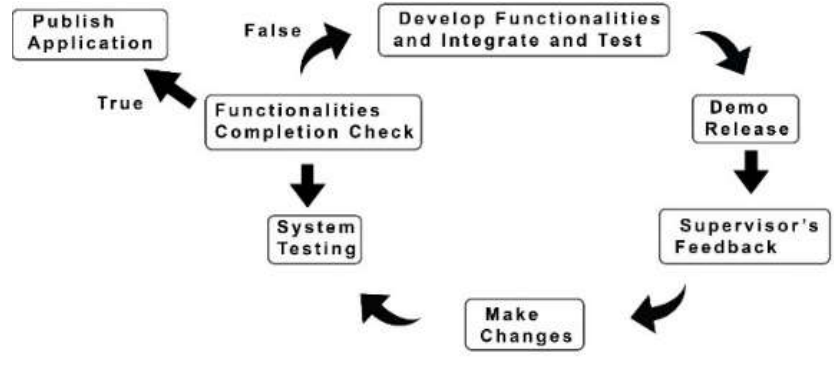

Figure 1. Agile software development methodology

\section{B. Graphical user interface design}

The interfaces designed for this game is by following Norman's mobile usability principles. The game's GUI is based on [15]. The following describes how:

- consistent in design as every button will direct the user to the appropriate interface using the same transitioning patterns. These are important as having a consistent interface and system flow creates consistency and this helps users to know what to expect or how to carry out a task;

- visibility is clear and precise. All navigations are available on the interfaces with no decorations to the fonts and button, providing clarity. Clarity is critical to the elderlies as it becomes easier for them to navigate and achieve their objective for each task. This prevents frustration and increases the level of ease when using the application;

- mapping is represented by the interaction on the player side and interaction on the system side (dual-player game) and the winning patterns working at the backend. Mapping leads to immediate understanding, reducing cognitive load in terms of having to grasp the idea of how a function is used or activated;

- affordance is through the mapping and thus navigational buttons will be made to look more $3 \mathrm{D}$ in comparison to the rest of the graphics. This eases the user's experience in finding where the clickable objects are. This is important because it provides strong clues on how things should be operated and act as signifiers. Moreover, it was discovered that it is more optimal for elderlies if interfaces were simple in terms of intuitive operation and usability [16].

- The constraints are the amount of levels new or existing users can access. They are not allowed to play levels that are too high before completing the previous stages. For example, user would not be able to play level 2 if they cannot cope with level 1.

\section{SYSTEM DESCRIPTION}

The main menu is presented in Fig. 2 . 


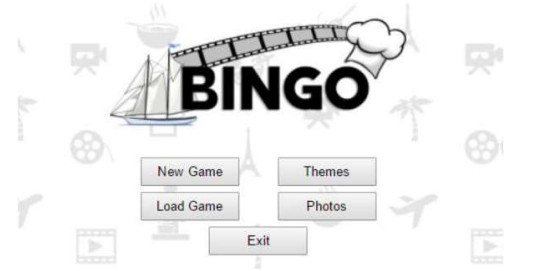

Figure 2. Main menu

By tapping on to the 'New Game' button, the user will be led to the following interface (Fig. 3). Once started, the timer of 3 minutes will start counting down. Every time the user manages to highlight the matching cell as the number currently displayed in 'Current Number', the next number to be called will then be displayed.

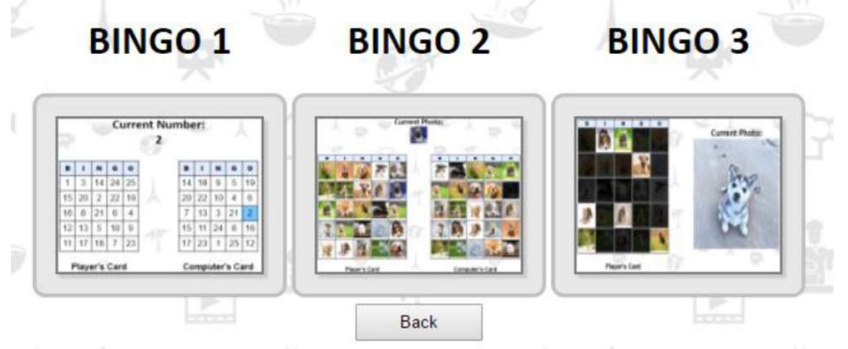

Figure 3. Three variants of the bingo game

The game will not start unless the user chooses to start the game. There are three different variants (Fig. 3) developed based on object-oriented analysis and design. Across the three variants, five winning patterns at each level work at the backend. The system monitors the user's interaction time and graduates the user from one winning pattern to the next, always ensuring user success.

The variants are as follow:

- The first (Fig. 4) would be the traditional bingo game played on a $5 \times 5$ card consisting of randomized numbers from 1 to 25 . Users are to tap the numbers that are currently being 'called out' by the application within a given time-frame. The time based on user testing is 3 minutes. We tested the time required on real users.

- The second (Fig. 5) is the same as the first. But instead of numbers, photos are used instead. Users can choose what photos they would like to be included in game play (travelling, movies or cooking - top three interests identified from a needs analysis survey). They can also choose to upload photos from their mobile device for game play.

- The third game (Fig. 6) is a memory game as the user will be required to remember the cell's photos behind every wrong cell they tap. The game will end after all the photos have been matched. There is no timer in this version of the game. If the cell tapped does not match the current photo being displayed, the cell will display the photo for 2 seconds before the 'current photo' changes. The cell will then flip back to being black.

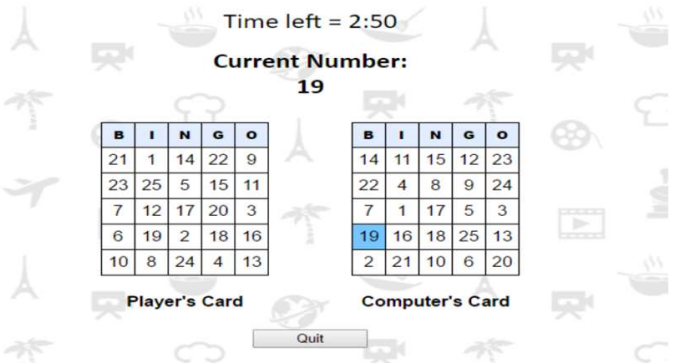

Figure 4. Bingo 1 (Traditional $5 \times 5$ bingo game)

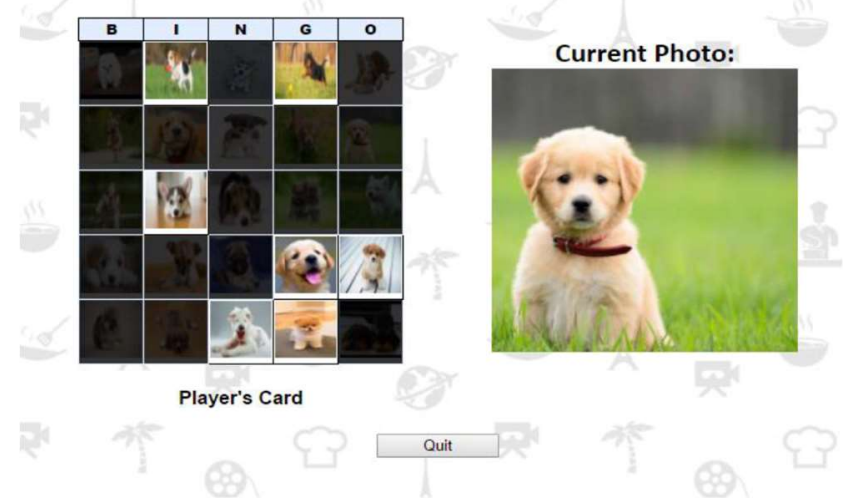

Figure 5. Bingo 2 (Traditional 5x5 bingo game with photos)

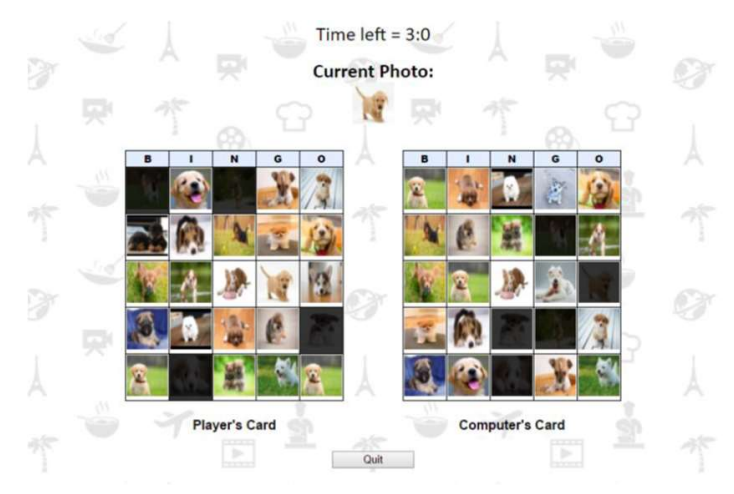

Figure 6. Bingo 3 (Memory game)

\section{USER TESTING}

A. Sample

The sample users are aged between 60 to 80 years old. A needs analysis questionnaire is given to the seniors based on the questionnaire used in [15]. Two sessions were conducted within two weeks on the $9^{\text {th }}$ and $16^{\text {th }}$ of June, 2017. There was a total of twenty-three (23) senior citizens. However, only 10 filled in the user testing questionnaire. A reason is that some have prior gaming experience but the majority do not.

\section{B. User testing questionnaires}

Three different questionnaires were handed out to the users for testing. The first questionnaire was on product assessment inclined towards user experience, obtained from 
the User experience website, the second on Norman's usability and the third on cognitive load.

\section{Product Assessment}

The questions with a scale from 1 to 7 for Product Assessment questionnaire are as follows

1) $1=$ Annoying, $7=$ Enjoyable

2) $1=$ Not Understandable, $7=$ Understandable

3) $1=$ Creative, $7=$ Dull

4) $1=$ Easy to Learn, $7=$ Difficult to Learn

5) $1=$ Valuable, $7=$ Inferior

6) $1=$ Boring, $7=$ Exciting

7) $1=$ Not Interesting, $7=$ Interesting

8) $1=$ Unpredictable, $7=$ Predictable

9) $1=$ Fast, $7=$ Slow

10) $1=$ Inventive, $7=$ Conventional

11) $1=$ Obstructive, $7=$ Supportive

12) $1=$ Good, $7=$ Bad

13) $1=$ Complicated, $7=$ Easy

14) $1=$ Unlikable, $7=$ Pleasing

15) $1=$ Usual, 7 = Leading Edge

16) $1=$ Unpleasant, $7=$ Pleasant

17) $1=$ Secure, $7=$ Not Secure

18) 1 = Motivating, $7=$ Demotivating

19) $1=$ Meets Expectations, $7=$ Does Not Meet Expectations

20) $1=$ Inefficient, $7=$ Efficient
21) $1=$ Clear, $7=$ Confusing

22) $1=$ Impractical, $7=$ Practical

23) $1=$ Organized, $7=$ Cluttered

24) $1=$ Attractive, $7=$ Unattractive

25) $1=$ Friendly, $7=$ Unfriendly

26) $1=$ Conservative, $7=$ Innovative

User testing outcomes are presented in Tables 1 and 2 . Human tendency in such scoring is to incline towards the right. As such, more Likert scales, will be designed with the most negative on the left and the most positive on the right.

To highlight the strengths of the system, Table 1 presents the progression from bad to good and Table 2 from good to bad. Table 1 shows that the scores are all above $50 \%$, i.e., above 4 except for unpredictable (with a score of 3.5). The timer merely works in the backend to gauge when to enable the user to go to the next level and not to press the user for time as in actual competitive system-user games. Hence, we find this exciting because though the challenge is not designed explicitly as a game mechanic, unpredictability is recognized as a challenge. As such, preliminary findings indicate that there is acceptance and user experience is promising.

Similarly, Table 2 shows that when there is a progression from positive to negative, the scores are within the 3.x range. This again attests that the negatives are not as negative. Results are actually rather promising.

TABLE 1. SCORES FOR QUESTIONS PROGRESSING FROM BAD TO GOOD

\begin{tabular}{|c|c|c|c|c|c|c|c|c|c|c|c|c|c|}
\hline Questions & Criterias/Users & U1 & $\mathbf{U} 2$ & U3 & \begin{tabular}{|l|l} 
& \\
\end{tabular} & U5 & \begin{tabular}{|l|l} 
\\
\end{tabular} & U7 & 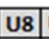 & U9 & U10 & Avg & Avg of Avg \\
\hline Q1 & Annoying (1) - Enjoyable (7) & 5 & 4 & 7 & 5 & 5 & 5 & 4 & 7 & 6 & 3 & 5.1 & \multirow{13}{*}{4.5692308} \\
\hline Q2 & Not understandable (1) - Understandable (7) & 5 & 3 & 5 & 4 & 5 & 5 & 4 & 5 & 6 & 3 & 4.5 & \\
\hline Q6 & Boring (1) - Exciting (7) & 5 & 2 & 5 & 4 & 5 & 6 & 5 & 5 & 4 & 4 & 4.5 & \\
\hline Q7 & Not interesting (1) - Interesting (7) & 4 & 3 & 5 & 5 & 6 & 4 & 4 & 1 & 5 & 3 & 4 & \\
\hline Q8 & Unpredictable (1) - Predictable (7) & 4 & 2 & 3 & 4 & 5 & 5 & 4 & 1 & 2 & 5 & 3.5 & \\
\hline Q11 & Obstructive (1) - Supportive (7) & 5 & 3 & 6 & 4 & 5 & 6 & 4 & 5 & 4 & 3 & 4.5 & \\
\hline Q13 & Complicated (1) - Easy (7) & 5 & 3 & 5 & 6 & 6 & 6 & 4 & 6 & 6 & 3 & 5 & \\
\hline Q14 & Unlikable (1) - Pleasing (7) & 5 & 5 & 6 & 5 & 5 & 6 & 4 & 7 & 5 & 3 & 5.1 & \\
\hline Q15 & Usual (1) - Leading Edge (7) & 5 & 4 & 3 & 5 & 3 & 5 & 4 & 5 & 4 & 3 & 4.1 & \\
\hline Q16 & Unpleasant (1) - Pleasant (7) & 5 & 4 & 6 & 5 & 5 & 5 & 5 & 6 & 5 & 3 & 4.9 & \\
\hline Q20 & Inefficient (1) - Efficient (7) & 5 & 6 & 6 & 5 & 6 & 6 & 5 & 6 & 5 & 4 & 5.4 & \\
\hline Q22 & Impractical (1) - Practical (7) & 5 & 3 & 5 & 5 & 5 & 5 & 5 & 6 & 4 & 3 & 4.6 & \\
\hline Q26 & Conservative (1) - Innovative (7) & 4 & 4 & 5 & 5 & 3 & 6 & 4 & 4 & 4 & 3 & 4.2 & \\
\hline \multicolumn{2}{|r|}{ Avg } & 5 & 4 & 5 & 5 & \begin{tabular}{|l|l}
5 & \\
\end{tabular} & \begin{tabular}{|l|l}
5 & \\
\end{tabular} & 4 & 5 & 5 & 3.3 & & \\
\hline & Avg of Avg & \multicolumn{10}{|c|}{4.569230769} & & \\
\hline
\end{tabular}

TABLE 2. SCORES FOR QUESTIONS THAT HAVE A SCALE FROM GOOD TO BAD

\begin{tabular}{|c|c|c|c|c|c|c|c|c|c|c|c|c|c|}
\hline Questions & Criterias / Users & U1 & $\mathbf{U 2}$ & U3 & U4 & us & U6 & U7 & U8 & ug & U10 & Avg & Avg of Avg \\
\hline $\mathrm{Q}_{3}$ & Creative (1) - Dull (7) & 5 & 3 & 3 & 5 & 4 & 6 & 3 & 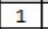 & 4 & 4 & 3.8 & \multirow{13}{*}{3.4769231} \\
\hline Q4 & Easy to learn (1) - Difficult to learn (7) & 3 & 4 & 7 & 4 & 3 & 4 & 5 & 1 & 3 & 1 & 3.5 & \\
\hline Q5 & Valuable (1) - Inferior (7) & 5 & 3 & 3 & 5 & 3 & 4 & 3 & 2 & 4 & 4 & 3.6 & \\
\hline$\alpha 9$ & Fast (1) - Slow (7) & 5 & 3 & 6 & 4 & 6 & 4 & 4 & 4 & 4 & 3 & 4.3 & \\
\hline Q10 & Inventive (1) - Conventional (7) & 5 & 3 & 3 & 5 & 2 & 4 & 4 & 4 & 4 & 3 & 3.7 & \\
\hline Q12 & Good (1) - bad (7) & 4 & 4 & 2 & 4 & 2 & 3 & 3 & 2 & 3 & 2 & 2.9 & \\
\hline Q17 & Secure (1) - Not Secure (7) & 4 & 4 & 3 & 6 & 2 & 6 & 4 & 2 & 4 & 4 & 3.9 & \\
\hline Q18 & Motivating (1) - Demotivating (7) & 3 & 5 & 3 & 6 & 3 & 3 & 3 & 1 & 2 & 4 & 3.3 & \\
\hline Q19 & Meets expectations (1) - Does not meet expectations (7) & 4 & 5 & 3 & 3 & 2 & 3 & 4 & 4 & 2 & 4 & 3.4 & \\
\hline Q21 & Clear (1) - Confusing (7) & 4 & 4 & 3 & 4 & 2 & 3 & 5 & 2 & 3 & 4 & 3.4 & \\
\hline Q23 & Organised (1) - Cluttered (7) & 3 & 3 & 3 & 3 & 2 & 4 & 3 & 4 & 3 & 3 & 3.1 & \\
\hline Q24 & Attractive (1) - Unattractive (7) & 3 & 4 & 3 & 3 & 3 & 3 & 4 & 2 & 3 & 3 & 3.1 & \\
\hline Q25 & Friendly (1) - Unfriendly (7) & 3 & 5 & 3 & 3 & 3 & 4 & 4 & 1 & 3 & 3 & 3.2 & \\
\hline \multirow{2}{*}{\multicolumn{2}{|c|}{ Avg }} & 4 & 4 & 3 & 4 & 3 & 4 & 4 & 2 & 3 & 3.2 & & \\
\hline & & \multicolumn{10}{|c|}{3.476923077} & & \\
\hline
\end{tabular}

A drill-down analysis (Table $3 \mathrm{a}$ ) reveals that the most positive attributes are efficient, enjoyable, exciting, and pleasant. For question 26, some respondents did not fill in and thus the total responses is less than 10 . 
TABLE 3A. TOP POSITIVE ATTRIBUTES FROM TABLE 1

\begin{tabular}{|l|l|l|l|}
\hline Question & Attribute & $\begin{array}{l}4 \text { and } \\
\text { above }\end{array}$ & Below 4 \\
\hline Q20 & Efficient & 10 & 0 \\
\hline Q1 & Enjoyable & 9 & 1 \\
\hline Q6 & Exciting & 9 & 1 \\
\hline Q16 & Pleasant & 9 & 1 \\
\hline Q2 & Understandable & 8 & 2 \\
\hline Q11 & Supportive & 8 & 2 \\
\hline Q14 & Pleasing & 8 & 2 \\
\hline Q22 & Practical & 8 & 2 \\
\hline Q7 & Interesting & 7 & 3 \\
\hline Q13 & Easy & 7 & 3 \\
\hline Q15 & Leading edge & 7 & 3 \\
\hline Q8 & Predictable & 6 & 4 \\
\hline Q26 & Innovative & 3 & 2 \\
\hline
\end{tabular}

There is consistency in findings between Tables $3 a$ and $3 b$, with the top 5 attributes in Table 3 b confirming the system's efficiency, enjoyability, excitingness and pleasantness (attractiveness).

TABLE 3B. TOP POSITIVE ATTRIBUTES FROM TABLE 2.

\begin{tabular}{|l|l|l|l|}
\hline Question & Attribute & $\begin{array}{l}\text { Below } \\
4\end{array}$ & $\begin{array}{l}4 \text { and } \\
\text { above }\end{array}$ \\
\hline Q24 & Attractive & 8 & 2 \\
\hline Q25 & Friendly & 7 & 3 \\
\hline Q23 & Organized & 7 & 3 \\
\hline Q18 & Motivating & 7 & 3 \\
\hline Q12 & Good & 7 & 3 \\
\hline Q21 & Clear & 5 & 5 \\
\hline Q19 & Meets expectations & 5 & 5 \\
\hline Q5 & Valuable & 5 & 5 \\
\hline Q4 & Easy to learn & 5 & 5 \\
\hline Q10 & Inventive & 4 & 6 \\
\hline Q3 & Creative & 4 & 6 \\
\hline Q17 & Secure & 3 & 7 \\
\hline Q9 & Fast & 2 & 8 \\
\hline
\end{tabular}

\section{Norman's usability testing}

So as to confirm our findings above, another study on ten seniors (not from the D'Happy Club) but within the same age group, is carried out using Norman's usability design principles. The questions for Donald Norman's questionnaire are as follows:

1) Could you navigate the application easily?

2) Are the words clear enough?

3) Are the photos clear enough?

4) Could you identify the places that you could tap easily?

5) Could you play all three (3) games easily?

6) Would you prefer the game in portrait or landscape view?

7) Would you prefer the game on your phone or on the computer?

8) What do you think about the overall design of this game?
As shown in Tables $4 \mathrm{a}$ and $4 \mathrm{~b}$, most users involved in the user testing could navigate the application easily and identify the places that they could tap easily. The words and photos available in the game were also adequate in terms of clarity. Hence, there is adequate affordance though embedded.

TABLE 4A. DATA COLLECTED FROM DONALD NORMAN'S QUESTIONNAIRE.

\begin{tabular}{|c|l|l|l|l|l|l|l|l|}
\hline Users / Questions & Q1 & Q2 & Q3 & Q4 & Q5 & Q6 & Q7 & Q8 \\
\hline U1 & Yes & Absolutely Yes & Yes & Yes & Yes & Landscape & Computer & Good \\
\hline U2 & Yes & Neutral & Yes & Neutral & Yes & Landscape & Computer & Good \\
\hline U3 & Yes & Yes & Yes & Yes & Yes & Landscape & Phone & Good \\
\hline U4 & Yes & Yes & Neutral & Yes & Neutral & Landscape & Computer & Good \\
\hline U5 & Yes & Yes & Neutral & Yes & Yes & Landscape & Phone & Good \\
\hline U6 & Absolutely Yes & Absolutely Yes & Yes & Yes & Neutral & Portrait & Phone & Good \\
\hline U7 & Yes & Yes & Yes & Neutral & Yes & Portrait & Phone & Good \\
\hline U8 & Yes & Yes & Neutral & Yes & Yes & Landscape & Computer & Good \\
\hline U9 & Yes & Yes & Yes & Yes & Yes & Portrait & Phone & Good \\
\hline U10 & Yes & Yes & Yes & Yes & Yes & Portrait & Phone & Good \\
\hline
\end{tabular}

TABLE 4B. FINER ANALYSIS WITH REGARDS TO LAYOUT

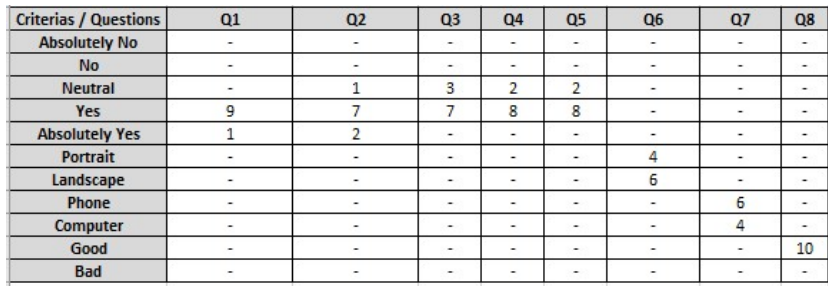

Other than that, the users preferred the application in landscape mode, hence the game was designed in that view initially via HTML and CSS. Majority also preferred the game to be on the computer. The game is already made available on Web version. Lastly, all of the testers rated the overall design of the application as good.

\section{E. Cognitive load testing}

Based on the above positive results, we tested on the latter group of active seniors. Findings (Tables 5a, 5b and 5c) are similar as the above.

Based on the analysis and the majority's given values, the users did not require a lot of mental effort to finish the task. It was easy to finish the task, and the task that was required to complete held the user's attention. Moreover, the task that they needed to perform stimulated their curiosity and kept their attention, the tasks had relevant to the user's life and there were sufficient instructions to show the users how to perform the tasks. They were positive that they had the ability to complete the task, were confident, and that the tasks were challenging for them. Lastly, they were satisfied, and pleased with the application. Therefore, the overall pros have outweighed the cons. 
TABLE 5A. QUESTIONS THAT HAVE A SCALE FROM GOOD TO BAD: 29\% (STILL INCLINED TOWARDS THE LEFT SCALES, I.E. THE POSITIVES)

\begin{tabular}{|c|c|c|c|c|c|c|c|c|c|c|c|}
\hline No. & Questions & Cinterias & U1 U2 & & U4 U. & & 070 & U8 U9 & 410 & & Avg of Avg \\
\hline & Degree of difficulty & Very easy (1) - Very difficult (7) & 23 & 1 & \begin{tabular}{|l|l|}
4 & 1 \\
\end{tabular} & 12 & 21 & 13 & 2 & 2.1 & \\
\hline 6 & $\begin{array}{l}\text { Customizing flexibility encourages } \\
\text { pariticipant to engage in activitites }\end{array}$ & $\begin{array}{l}\text { Strongly agree (1)- } \\
\text { Strongly disagree (7) }\end{array}$ & $\begin{array}{ll}4 & 5\end{array}$ & 3 & \begin{tabular}{l|l}
5 & 1
\end{tabular} & 12 & 21 & 11 & 2 & 2.6 & 2.7 \\
\hline 7 & $\begin{array}{l}\text { Good clarity for participants to clear } \\
\text { activities }\end{array}$ & $\begin{array}{l}\text { Strongly agree (1)- } \\
\text { Strongly disagree (7) }\end{array}$ & \begin{tabular}{l|l}
6 & 7
\end{tabular} & 6 & 71 & 11 & 21 & 11 & 2 & 3.4 & \\
\hline \multicolumn{3}{|c|}{ Avg } & 45 & 3 & $\begin{array}{lll}5 & 1\end{array}$ & 12 & 21 & 12 & 2 & & \\
\hline \multicolumn{3}{|c|}{ Avg of Avg } & \multicolumn{7}{|c|}{2.7} & & \\
\hline
\end{tabular}

TABLE 5B. QUESTIONS THAT HAVE A SCALE FROM BAD TO GOOD (1): 76\% (STILL INCLINED TOWARDS THE RIGHT SCALES, I.E., THE POSITIVES)

\begin{tabular}{|c|c|c|c|c|c|c|c|c|c|c|c|}
\hline No. & Questions & Criterias & U1 U & 203 & 04 & & U7 & & g9 110 & 0 Avg & Avg of Avg \\
\hline & Use a lot of mental effort & Not at all true (1) - Very true (7) & \begin{tabular}{|l|l}
42 \\
2
\end{tabular} & 1 & 4 & 13 & & 1 & $\begin{array}{l}3 \quad 3 \\
\end{array}$ & 2.5 & \multirow{10}{*}{5.31} \\
\hline & Activities holds attention & Not at all true (1) - Very true (7) & 55 & 6 & 6 & $\begin{array}{ll}6 & 5 \\
\end{array}$ & 6 & 6 & $\begin{array}{l}5 \\
5 \\
\end{array}$ & 5.5 & \\
\hline 4 & Task stimulates curiosity & Not at all true (1) - Very true (7) & \begin{tabular}{l|l}
6 & 7 \\
\end{tabular} & 4 & 7 & 75 & 5 & 4 & \begin{tabular}{l|l}
6 & 5 \\
\end{tabular} & 5.6 & \\
\hline 5 & Variety of activities keep attention & Not at all true (1) - Very true (7) & \begin{tabular}{|l|l|l}
5 & 6 \\
\end{tabular} & 6 & 4 & \begin{tabular}{c|c}
5 \\
4
\end{tabular} & 5 & 4 & \begin{tabular}{l|l}
6 & 4 \\
\end{tabular} & 4.9 & \\
\hline 8 & Task are relevant to participant's life & Not at all true (1) - Very true (7) & \begin{tabular}{|l|l}
5 & 5 \\
\end{tabular} & 6 & 4 & 65 & 6 & 4 & \begin{tabular}{|l|l}
5 & 4 \\
\end{tabular} & 5 & \\
\hline 9 & $\begin{array}{l}\text { Sufficient instructions for performing } \\
\text { task provided }\end{array}$ & Not at all true (1) - Very true (7) & 76 & 5 & 5 & 77 & 6 & 7 & 7 & 6.4 & \\
\hline 10 & $\begin{array}{l}\text { Confident having the ability to perform } \\
\text { task }\end{array}$ & Not at all true (1) - Very true (7) & $2: 1$ & 7 & 4 & & 7 & 7 & 6 & 5.5 & \\
\hline 11 & Confident in completing task & Not at all true (1) - Very true (7) & 65 & 7 & 5 & 77 & 7 & 7 & $\begin{array}{l}7 \\
7\end{array}$ & 6.5 & \\
\hline 12 & Activities are challenging & Strongly agree (1)- & 12 & 3 & 7 & 77 & 7 & 6 & \begin{tabular}{l|l}
7 & 6 \\
\end{tabular} & 5.3 & \\
\hline 13 & Task & Very dissstisfied (1) - Very satisfied (7) & \begin{tabular}{|l|l}
5 & 5 \\
\end{tabular} & 6 & 7 & \begin{tabular}{l|l}
6 & 6 \\
\end{tabular} & 5 & 7 & $\begin{array}{ll}6 & 6 \\
\end{array}$ & 5.9 & \\
\hline \multicolumn{3}{|r|}{ Avg } & \begin{tabular}{|l|l}
5 & 4 \\
\end{tabular} & 5 & 5 & \begin{tabular}{l|l}
6 & 6 \\
\end{tabular} & 6 & 5 & \begin{tabular}{l|l}
6 & 5.3 \\
\end{tabular} & & \\
\hline & Avg of & & \multicolumn{8}{|c|}{531} & \\
\hline
\end{tabular}

TABLE 5C. QUESTIONS THAT HAVE A SCALE FROM BAD TO GOOD (2): 69\% (STILL INCLINED TOWARDS THE RIGHT SCALES, I.E., THE POSITIVES)

\begin{tabular}{|c|c|c|c|c|c|c|c|c|c|}
\hline No. & Questions & Criterias & \begin{tabular}{|l|l|l|l|} 
& $\cup 1$ & $\cup 2$ & $\cup 3$ \\
\end{tabular} & 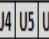 & \begin{tabular}{|l|l|}
166 & 07 \\
\end{tabular} & \begin{tabular}{|l|l|l|}
$7 \cup 8$ & 09 \\
\end{tabular} & \begin{tabular}{l|l}
1010 \\
9
\end{tabular} & Avg & Avg of Avg \\
\hline 14 & Task & Very displeased (1) - Very pleased (7) & \begin{tabular}{|l|l|l|}
2 & 2 & 1 \\
\end{tabular} & .76 & \begin{tabular}{|l|l|}
6 & 6 \\
\end{tabular} & 76 & $\begin{array}{lll}6 & 7\end{array}$ & 4.9 & \\
\hline 15 & Task & Very frussated (1) - Very contented (7) & \begin{tabular}{|l|l|l|}
1 & 1 & 1 \\
\end{tabular} & .7 & \begin{tabular}{|l|l|}
7 & 6 \\
\end{tabular} & 76 & $\begin{array}{lll}6 & 7\end{array}$ & 4.8 & 4.81481481 \\
\hline 16 & Task & Very unpleasant (1) - Very pleassant (7) & \begin{tabular}{|l|l|l|}
1 & 1 & 1 \\
\end{tabular} & 7. & \begin{tabular}{|l|l|}
7 & 6 \\
\end{tabular} & 76 & $\begin{array}{lll}6 & 7 \\
\end{array}$ & 4.8 & \\
\hline \multicolumn{3}{|c|}{ Avg } & \begin{tabular}{|l|l|l|}
1 & 1 & 1 \\
\end{tabular} & .7 & \begin{tabular}{|l|l|}
7 & 6 \\
\end{tabular} & 76 & $\begin{array}{ll}6 & 7 \\
\end{array}$ & & \\
\hline \multicolumn{3}{|c|}{ Avg of avg } & \multicolumn{6}{|c|}{4.814814815} & \\
\hline
\end{tabular}

\section{CONCLUSION}

Consistent with Norman's usability principles, and the Technology Acceptance Model, the simplicity of the design, ease of use and usefulness have been regarded as of primary importance. Furthermore, since all data will be stored in Firebase, we will carry out simple analytics in order to identify how to further meet the needs of the elderlies. It is especially hoped that the affordances factored in would be able to help them to have fun, subsequently, more interests and socio- cognitive- engagements and happier times.

\section{ACKNOWLEDGEMENT}

This study is funded under the Malaysian Ministry of Education's Fundamental Research Grant Scheme. We thank Adjunct Assoc. Prof. Dr. Siew-Fan Wong for the design of the cognitive load questionnaire.

\section{REFERENCES}

[1] TheSundaily. "M'sia to become ageing population country by 2030." | [ONLINE] Available at:

http://www.thesundaily.my/news/1357641 [Accessed 18 October 2016].

[2] S. Mohd Sidik. "The Prevalence of Depression Among the Elderly in Sepang, Selangor". 2004. [ONLINE] Available at: http://www.e-mjm.org/2004/v59n1/Depression.pdf [Accessed 18 October 2016].

[3] A. Rashid, A. Manan and S Rohana. "Depression Among The Elderly Malays Living In Rural Malaysia". 2010. [ONLINE] Available at: http://ispub.com/IJPH/1/2/4793 [Accessed 18 October 2016].

[4] Care Giver Stress. "5 Benefits of Technology to Share with Seniors and Their Caregivers". 2016. [ONLINE] Available at: http://www.caregiverstress.com/geriatric-professionalresources/5-benefits-of-technology-to-share-with-seniorsand-their-caregivers/ [Accessed 1 October 2016].

[5] R. Wong. No room for old folk in Malaysia. 2014. [ONLINE] Available at: http://www.theheatmalaysia.com/SOCIOECONOMICS/No-room-for-old-folk-in-Malaysia [Accessed 24 October 2016].

[6] Ruhani Binti Haji Zawawi. Active ageing in Malaysia. 2013. [ONLINE] Available at: http://www.mhlw.go.jp/stf/shingi/2r98520000036ylaatt/2r98520000036yqa_1.pdf [Accessed 2 October 2016].

[7] J. Wakefield. "The generation that tech forgot". 2015 [ONLINE] Available http://www.bbc.com/news/technology-32511489 [Accessed 24 October 2016].

[8] D. Orenstein. "Elderly brains learn, but maybe too much". 2014. [ONLINE] Available at: https://news.brown.edu/articles/2014/11/irrelevant [Accessed 29 October 2016].

[9]M. Wilson. "When is Learnability More Important than Usability?" 2011. [ONLINE] Available at: http://www.uxbooth.com/articles/when-is-learnability-moreimportant-than-usability/ [Accessed 2 October 2016].

[10] Meko. 2016. EA's Monopoly Bingo app reviewed for iOS and Android. [ONLINE] Available at: http://casinoapp.eu/monopoly-bingo/ [Accessed 29 October 2016].

[11] S. Y. Guy, and C. S. Lee, "Web and augmented realityenhanced portal for youths and seniors," Capstone project, Sunway University, Malaysia.

[12]K. Matz. "Donald Norman's design principles for usability". 2012. [ONLINE] Available at http://architectingusability.com/2012/06/28/donald-normansdesign-principles-for-usability/ [Accessed 24 October 2016].

[13]Bingo Bash - Android Apps on Google Play. 2016. Bingo Bash - Android Apps on Google Play. [ONLINE] Available at:

https://play.google.com/store/apps/details?id=air.com.bitrhy mes.bingo\&hl=en [Accessed 24 October 2016].

[14]M. Kennedy. "Case Study: Applying Agile Software Methods to Systems Engineering". 2016 [ONLINE] Available at: https://www.csiac.org/journal-article/case-study-applyingagile-software-methods-to-systems-engineering/ [Accessed 31 October 2016].

[15]Don Norman. "Design of Everyday Things". 2013. [ONLINE] Available at: $\quad \mathrm{http} / / / \mathrm{cc}$.droolcup.com/wpcontent/uploads/2015/07/The-Design-of-Everyday-ThingsRevised-and-Expanded-Edition.pdf 